\title{
A Rare Outbreak of Foot and Mouth Disease in Captive Yaks
}

\section{Muhammad Abubakar ${ }^{*}$, Aatka Jamil ${ }^{2}$, Shumalla Manzoor ${ }^{2}$, Еhtisham-ul Hae Khan ${ }^{2}$, MuHAMmad JaVEd ARShad ${ }^{2}$}

\author{
${ }^{1}$ National Veterinary Laboratory, Park Road, Islamabad, Pakistan; ${ }^{2}$ FAO National Project, Progressive Control of \\ Foot and Mouth Disease in Pakistan (GCP/PAK/123/USA), Islamabad, Pakistan.
}

\begin{abstract}
Foot and Mouth Disease (FMD) is the most important infectious disease of cloven footed animals. It has wide range of hosts but mostly it occurs in cattle and buffaloes. In this report, a rare outbreak of FMD in wild yaks kept at wild life park Murree is described. It was worth-mentioning that clinical lesions were same in severity as in large ruminants. After laboratory analysis, the suspected samples were confirmed as FMD virus serotype A. Based on this report; it is recommended that any control program on FMD should consider the population of yaks and other wild ruminants for vaccination.
\end{abstract}

Keywords $\mid$ Foot and mouth disease, Serotype, Yak, Outbreak, ELISA

Editor | Muhammad Zubair Shabbir, Assistant Professor, Quality Operations Laboratory, University of Veterinary and Animal Sciences, Lahore, Pakistan.

Received | March 30, 2015; Revised | October 24, 2015; Accepted | October 26, 2015; Published | November 09, 2015

*Correspondence | Muhammad Abubakar, National Veterinary Laboratory, Park Road, Islamabad, Pakistan; Email: mabnvl@gmail.com

Citation | Abubakar M, Jamil A, Manzoor S, Khan EH, Arshad MJ (2015). A rare outbreak of Foot and Mouth Disease in captive yaks. Res. J. Vet. Pract. 3(4): 80-82.

DOI | http://dx.doi.org/10.14737/journal.rjvp/2015/3.4.80.82

ISSN | 2308-2798

Copyright $(\odot 2015$ Abubakar et al. This is an open access article distributed under the Creative Commons Attribution License, which permits unrestricted use, distribution, and reproduction in any medium, provided the original work is properly cited.

$\mathrm{F}$ oot and mouth disease is highly infectious disease of cloven hoofed animals. It is associated with economic losses rather than mortality of animals. Pakistan is an endemic country for Foot and Mouth Disease (FMD) and its prevalence is $33.2 \%$ (Abubakar et al., 2012; Abubakar et al., 2015). There are three serotypes of FMD (i.e., O, A and Asia1) which are predominantly present in Pakistan but it has been reported that there was a phenomena of sero-shift, at one time one serotype dominates over the others (Abubakar et al., 2012; Abubakar and Manzoor, 2013a; Abubakar et al., 2013b).

Classically, FMD is associated with mammalian species of Artiodactyla order but studies still give a long list of susceptible species which are other than cattle and buffaloes. The first case reported about a FMD outbreak in a zoo occurred at the Paris Zoo in 1937. So if we talk about control of FMD we should also focus on all susceptible species other than cattle and buffalo.

Yak is also one of the susceptible hosts for FMD. Data on an outbreak of FMD at the Rotterdam Zoo in 1951 have been retrieved from old zoo records and interviews with retired staff members. The head keeper of the yaks reported that yaks (Bos grunniens) the only animals having shown clinical signs during this outbreak (Schaftenaar, 2002). The yak (Bos grunniens and Bos mutus) is a long- haired mammal found throughout the Himalayan region of south Central Asia, the Tibetan Plateau and as far north as Mongolia and Russia.

In Pakistan, yaks are confined to the high plateau of the Northern Areas, from Gilgit to the valley of Ladakh. Yaks can survive at the altitudes above 5000 meters. The Hin$\mathrm{du}$ Kush Himalayas $(\mathrm{HKH})$ and Pamir mountain tract are key yak habitat where total global yak population as reported by FAO (2003) was 14.2 million of which $93 \%$ were in China, about $0.04 \%$ in Mongolia and $0.01 \%$ in Gilgit-Baltistan. Population of yaks was first estimated in the Northern Areas during 1984 through a study conducted by Pakistan Agricultural Research Council. According to this study, the population of yaks was 25 thousand. Latest during Livestock Census of 1996 it was reported that the number of yaks was 14.9 thousand. Yak is locally named as 'Dong' in Gilgit Baltistan, the male is popularly known as yak and the female is called yakmo. There are no reports about the status of FMD in yaks in the country. While in other south Asian countries such as Nepal it has been reported that FMD is $65 \%$ in yak population (Joshi et al., 1997). A rare outbreak was reported and investigated in yak at wild life park Murree and its detailed description is given below.

In the month of April 2014, an outbreak was reported at 
wild life park Murree. A large no of wild animals were present at that park but the clinical disease was observed in the yaks. There were total four adult yaks (two of each gender). Three out of four yaks were showing clinical signs of FMD, severe salivation and lesions in mucosa of mouth (Figure 1 and 2).

Samples were collected from oral lesions of all three affected yaks. These samples were collected in glycerol buffer and transported to National Veterinary Laboratories, Islamabad, Pakistan. All the suspected population including deer at that park was vaccinated against FMDV.

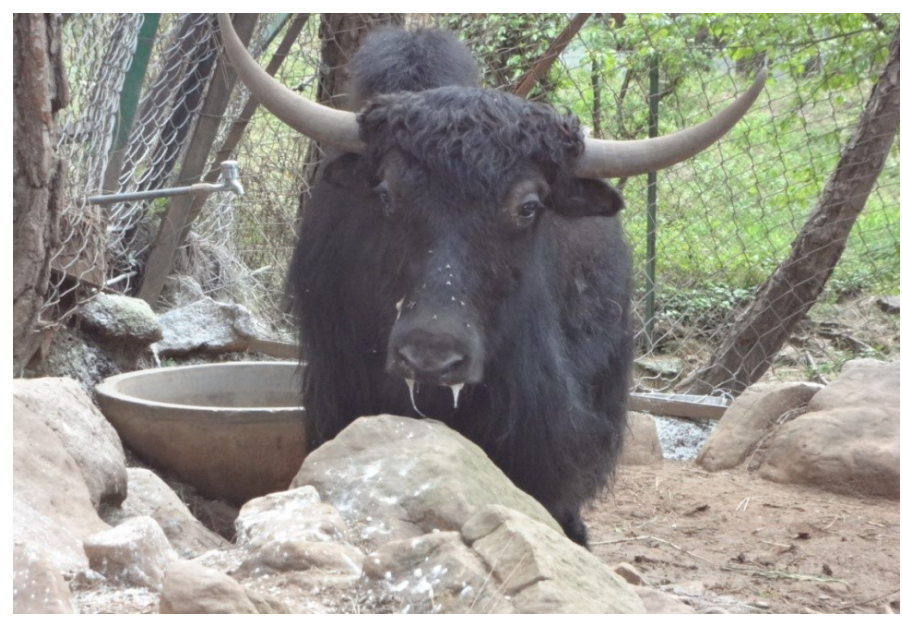

Figure 1: Svere salivation (a typical sign of FMD)

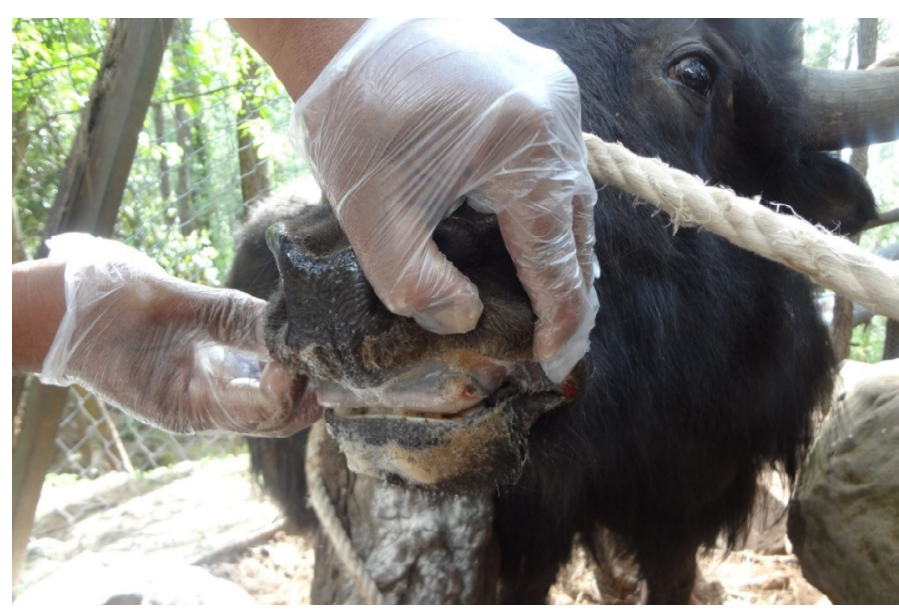

Figure 2: Ulcerative lessons on the gum and tongue of affected yak

These samples were then processed and suspension was made in Phosphate Buffer Saline (PBS). Samples were analyzed for against all three serotypes of FMDV found in Pakistan. ELISA for FMDV antigen detection and serotyping was performed by using kit manufactured by IZSLER, Brescia, Italy. A color reaction on the addition of enzyme substrate indicated a positive reaction and the results were read spectrophotometrically (Immunoskan, BDSL, Finland) at recommended wavelength $(450 \mathrm{~nm})$. In this case, an absorbance reading greater than 0.1 above background indicated a positive reaction; thus the confir- mation of FMD antigen and serotype was done.

According to results of antigen detection ELISA all three sampleswere positive againstserotype A of FMDV(Table1).

Table 1: Summary of sampling and results of FMDV outbreak

$\begin{array}{|lllll|}\begin{array}{l}\text { Animal } \\ \text { habitat }\end{array} & \begin{array}{l}\text { Animal } \\ \text { species }\end{array} & \begin{array}{l}\text { Total } \\ \text { animal }\end{array} & \begin{array}{l}\text { Clinically Affect- } \\ \text { ed animals }\end{array} & \begin{array}{l}\text { FMDV } \\ \text { Serotype }\end{array} \\ \begin{array}{l}\text { Wild } \\ \text { Life Park }\end{array} & \text { Yak } & 4 & 3 & \text { A } \\ & & & & \end{array}$

Although most of the reports of FMDV are in the domesticated animals, but there are few studies which report the occurrence of FMD in other wild species also. Ward et al. (2007) reported that wild deer and feral pigs might both amplify disease-spread and form a potential reservoir of FMD virus infection. In another study, it was detected that feral swine can easily acquire and transmit FMDV to other feral and to domestic swine and thereby pose a significant threat. Increased vigilance is required when conducting FMD surveillance because these animal exhibit delays in presenting clinical signs and lesions and often difficult to recognize (Mohamed et al., 2011). An outbreak of FMDV was reported by European Commission in 2011. It was reported that near the Turkish border of Balgaira wild boars got FMDV infection. So these wild animals can be a source of FMD even in disease free areas. Similarly, Pineda et al. (2010) stated that although US is FMD free but introduction of FMDV from wild pigs into a dairy or beef herd could result in a large and rapidly spreading outbreak, potentially affecting large numbers of herds.

There are studies which indicate that yak can remain carrier for FMDV. Chang et al. (2013) reported that when yaks were infected experimentally with FMDV (O/Akesu/58). All the yaks showed clinical signs and kept carrier status for at least 8 months after infection. This report supports our findings that yaks are potential host for FMDV. If we discuss about FMDV serotypes causing disease in yaks then there are reports in literature that any prevalent serotype in the area can infect yaks also. This is also supported by Das (2010) who vaccinated yaks. The vaccine was trivalent having all three serotypes $\mathrm{O}, \mathrm{A}$ and $\mathrm{Asia}-1$ prevalent in India and when sera were tested for the presence of antibodies yaks showed good immune response against all serotypes.

So it is concluded that any policy about the control and ultimately eradiation of FMD from Pakistan should consider the huge population of yaks for vaccination.

\section{CONFLICT OF INTERES}

There is no conflict of interest. 


\section{ACKNOWLEDGEMENT}

The efforts of ELISA staff at National Veterinary laboratory, Islamabad and FAO funded projects are acknowledge.

\section{AUTHORS' CONTRIBUTION}

MA, MJA, EHK performed the study, attended outbreak and collected samples. MA, AJ and SM tested the samples and prepared initial draft while all authors checked and agreed with final manuscript.

\section{REFERENCES}

-Abubakar M, Arshed MJ, Ali Q, Hussain M (2012). Spatial trend of Foot and Mouth Disease Virus (FMDV) serotypes in cattle and buffaloes, Pakistan. Virol. Sin. 27(5): 320-323. http://dx.doi.org/10.1007/s12250-012-3271-8

-Abubakar M, Manzoor S (2013a). Epidemiological aspects of Foot and Mouth Disease outbreak in a sheep herd. Pak. J. Life Soc. Sci. 11(3): 244-246.

-Abubakar M, Khan E, Arshed MJ, Hussain M, Ali Q, Afzal M (2013b). Mortality rate in association with Foot and Mouth Disease outbreaks in cattle and buffaloes, Pakistan. ASM Sci. J. 7(2): 139-143.

-Abubakar M, Khan EH, Arshed MJ, Gonzales J, Ferrari G, Hussain M, Ali Q (2015). An appraisal on the occurrence of Foot-and-Mouth Disease virus serotypes in cattle and buffaloes, Pakistan. Arch. Virol. http://dx.doi.org/10.1007/ s00705-015-2409-z

-Chang H, Ma Y, Lin T, Cong G, Du J, Ma J (2013). Foot-and- mouth disease virus carrier status in Bos grunniens yaks. Virol J. 10:81. doi: 10.1186/1743-422X-10-81.

-Das D (2010). Evaluation of immune response of yak after foot and mouth disease vaccine. Onderstepoort J Vet Res., ISSN: 0030-2465 (print) ISSN: 2219-0635(online)

-FAO (2003). The Yak-second edition. http://www.fao.org/ docrep/006/ad347e/ad347e00.htm

-European Commission (2011). Foot and Mouth Disease case confirmed in wild boar in Bulgaria. Urgent Fax - 05/01/2011 13:40 Received 05/01/2011.

-Joshi D, Lensch D, Sasaki J, Hentsch M, (1997). Yak production in central Asian highlands. Proceedings of the second international congress on Yak, Xining, P. R. China, 1-6 September, 1997. pp. 229-233. ISBN: 7-225-01162-6.

-Mohamed F, Swafford S, Petrowski H, Bracht A, Schmit B, Fabian A, Pacheco J, Hartwig E, Berninger M, Carrillo C, Mayr G, Moran1 K, Kavanaugh D, Leibrecht H, White W, Metwally S (2011). Foot-and-Mouth Disease in feral swine: Susceptibility and transmission. Transbound. Emerg. Dis. http://dx.doi.org/10.1111/j.1865-1682.2011.01213

-Pineda-Krch M, O’Brien JM, Thunes C, Carpenter TE (2010). Potential impact of introduction of foot-and mouth disease from wild pigs into commercial livestock premises in California. Am. J. Vet. Res. 71: 1. http://dx.doi.org/10.2460/ ajvr.71.1.82

-Schaftenaar W (2002). Use of vaccination against foot and mouth disease in zoo animals, endangered species and exceptionally valuable animals. Rev. Sci. Tech. Off. Int. Epiz. 21(3): 613-623.

-Ward MP, Laffan SW, Highfield LD (2007). The potential role of wild and feral animals as reservoirs of foot-andmouth disease. Prevent. Vet. Med. 80: 9-23. http://dx.doi. org/10.1016/j.prevetmed.2007.01.009 